\title{
Las torres del litoral en el reinado de Felipe II: Una arquitectura para la defensa del territorio (I)
}

\author{
alicia Cámara muñoz
}

"... he tenido por mi parte consideración a que esta costa como la que queda de España es como una cerca de muralla que la cierra toda, y que los puertos y los otros lugares son las puertas del Reyno y los baluartes del y estas torres son las garitas de los centinelas que los velan de dia y de noche y que estando esta cerca bien reparada y bien guardada estará muy seguro lo demás...» (Juan Baustista Antonelli, año 1570)

Entre las necesidades defensivas de la monarquía española a lo largo del siglo XVI, el peligro que supusieron los corsarios en el Mediterráneo se sumó al miedo ante una posible invasión desde el norte de África, que hubiera podido contar con la ayuda de los moriscos del interior de la península. A mediados del siglo XVI el temor aumentó, en función de los cambios que se habian producido en el norte de África, al unirse un enemigo hasta entonces dividido. En la década de los ochenta, y a pesar de que los piratas berberiscos ya no contaran con la colaboración turca, no cejaron en sus destructivas incursiones. Parece, no obstante, que tanto a Carlos $\mathrm{V}$ como a Felipe II les preocupó durante un tiempo más el peligro que suponía la armada otomana, sobre todo por sus alianzas con los franceses, que los ataques corsarios, pese a lo que éstos interferian 
en el comercio y las comunicaciones '. Aunque no fuera aceptada oficialmente a mediados del siglo la existencia de un peligro inmediato de invasión desde el Magreb, con el tiempo eso cambió. El hecho es que las costas del sur y este peninsulares se vieron constantemente atacadas por piratas y corsarios, y que fue necesario adaptar esas costas a dicha realidad. Unos años especialmente ricos en informes e intervenciones en las fortificaciones del litoral fueron los siguientes a 1568, cuando después de la rebelión de los moriscos de Granada se acrecentaron los temores en otras zonas a un posible ataque otomano o invasión de Berberia apoyado desde dentro.

Las torres que se levantaron por todo el litoral a lo largo del siglo fueron parte de un sistema de vigilancia de las costas que permitía avisar rápidamente del ataque, para que pudieran intervenir las gentes de armas de las fortalezas y las ciudades cercanas. Se utilizaron las torres o almenaras en las que se encendian hogueras por la noche y humaredas durante el día para avisar de la presencia enemiga, siendo este un sistema que de manera directa los cristianos tomaron de los musulmanes, de ahi el nombre de almenara, pero que en realidad data de tiempos más antiguos, pues Polibio se refirió a ese sistema de señales en las fronteras imperiales y es famosa la cita de Plinio acerca de las torres de Anibal en las costas españolas y africanas, que avisaban del peligro mediante el fuego. El mismo ingeniero Juan Bautista Antonelli, cuyas palabras abren este estudio, citó a Plinio como fuente de autoridad cuando argumentó las razones por las que las torres de la costa del reino de Murcia se debian hacer de tapiería y no de mampostería (parecer del que disentía Vespasiano Gonzaga), pues de tapias eran las que Anibal hizo en la costa de España según Plinio.

Estos precedente púnicos y romanos enlazan con las torres construidas por bizantinos y árabes, que a su vez enlazan con las que jalonaron las costas de los reinos de la monarquía española en el Mediterráneo. Cuando Vander Hammen recordó las grandes obras de Felipe II, no dejo de citar las torres - sobre todo las de los Alfaques de Tortosa- «que ay desde Colibre hasta Ayamonte para el aviso en toda la costa, dichas comúnmente Atalayas" y añadió que de la misma manera "cercó los Reynos de Napoles y Sicilia" con torres. De hecho, en Sicilia, ya con el virrey Juan de Vega (1547-1557) se construyeron una

' Rodriguez Salgado, M., The Changing Face of Empire, Charles V. Philip II and Habsburg Authority, 1551-1559. Cambridge, 1988, págs. 256-266. Sobre la situacion politica en el norte de Africa y sus repercusiones en Espana, vease sobre todo HESs, A., The forgotten frontier, Chicago, 1978. 
serie de torres con esa función de vigilancia, aunque fue el virrey Marco Antonio Colonna quien organizó definitivamente ese sistema, siendo el ingeniero Camilliani el encargado de informar (1583-84) acerca de ello tomando como base la descripción que Spannocchi habia hecho años antes. También en Nápoles se proyectó en el reinado de Felipe II un sistema de torres que, ya en 1532, había sido propuesto por el virrey Pedro de Toledo y, en Cerdeña, el virrey Miguel de Moncada se ocupó desde 1578 en que esa isla tuviera la protección que parecian poder ofrecer las torres costeras ${ }^{2}$.

Antes de referirnos al gran número de torres construidas en las costas y a su arquitectura, debemos someramente enumerar algunos de muchos ataques que hubo, pues sólo asi comprenderemos la necesidad de estas construcciones que protegieron el litoral contribuyendo a la idea de la península como algo cerrado y a salvo de ataques enemigos mediante la arquitectura militar (por sencilla y funcional que fuera la arquitectura de las torres, éstas fueron pieza esencial del sistema defensivo): en 1527 los piratas capturaron a veinticinco cautivos en Badalona y saquearon distintas playas de Cataluña; en 1543 los turcos atacaron Palamós y Rosas; en 1550 saquearon Cullera y Pollensa; ese mismo año de 1550 moros y turcos entraron en Benaimádena, saqueándola, aunque en este caso no se pudieron llevar cautivos; en 1551 los vecinos de esa villa volvian a expresar su temor ante la presencia de «muchos navios moros y turcos»; el conde de Tendilla escribia al principe Felipe en 1552 que sabía por el marqués de Vélez que Elche estaba cercada por tres mil moros, y que habia treinta fustas en la desembocadura del rio Guardamar; en 1558 Dragut desembarcó en Salou con más de cuatrocientos moros; ese mismo año de 1558 fue avisada Málaga de que ciento treinta galerăs turcas se dirigian a esa ciudad para saquear los Percheles y se tomaron todas las precauciones posibles aunque no llegó a producirse un ataque que en cambio si se produjo en 1566, capturando vecinos de dicho barrio del Perchel así como navíos del puerto; fray Gerónimo Hurtado, que escribió en el siglo XV! sobre Murcia, afirmaba que la catedral de obispado hubo de trasladarse de Cartagena a Murcia debido al "peligro de los moros de tierra y mar»; en 1566 penetraron los moros por un lugar de la costa del reino de Granada treinta kilómetros tierra adentro y

- Gamir Sandoval, A., Organización de la defensa de la costa del Reino de Granada. Granada, 1943 (Ed. facsimil, Granada, 1988), pags. 9-12. TABARELLI G. M. Casielli, Rocche e Mura diltalia, Bramante Editrice, 1983, MazzaAella, S. y ZancA, R., II libro delle torri, Falermo, 1985, CAmaRA, A. "Tiburcio Spannocchi, ingeniero mayor de los reinos de España», en Espacio, Tiempo y Forma, n. $2,1988$. 
se llevaron cuarenta y ocho cautivos, más noventa y nueve moriscos que huyeron con ellos; en 1573 corsarios berberiscos saquearon Cuevas de Almanzora, siendo uno de los casos más famosos por la cantidad de cautivos que se llevaron, entre ellos muchas mujeres y niños; Fernando Hurtado de Mendoza, Capitán General de la costa del Reino de Granada, recibió aviso en 1584 de que habian salido navios de Argel, previniendo para su defensa a toda la costa... ${ }^{3}$.

El peligro que suponian los corsarios se pone también de manifiesto por ejemplo en el hecho de que la Virgen del Rescate, del Convento de la Santísima Trinidad de Madrid, «llevaronla cautiva los Moros, de un lugar que saquearon en las costas de España. Estuvo algunos años en Argel, hasta que dos Religiosos la rescataron, sacándola del poder de quien no la conocia. Entró en processión en la Corte con los otros cautivos rescatados, quedandose con el nombre de la Virgen del Rescate " ${ }^{4}$. Además de todas estas noticias, que podrian multiplicarse, la literatura ha dejado magníficos ejemplos del tema de los cautivos cristianos en tierras moras, todo lo cual justificó el temor y la necesidad de defenderse que tuvieron las poblaciones costeras. Los ataques eran rápidos y jugaban con la sorpresa, de ahí la necesidad de las torres que avisaran del peligro. Poco frecuentes fueron en cambio noticias a la inversa como la que se produjo en 1589, cuando el marqués de Torrilla, hijo de Andrea Doria, apresó nueve galeotas de turcos en los Alfaques de Tortosa, capturando a 246 hombres de los 296 que iban en los barcos ${ }^{5}$. La monarquía planteó lo que era la guerra ofensiva de otra manera, pues lo que trató fue de controlar y conquistar las bases de que se servian los corsarios en el norte de África (y a esas conquistas estuvo ligado el mayor o menor peligro de las costas peninsulares) para sus incursiones ya que,

${ }^{3}$ Garcia Carcel, R., Historia de Cataluña, Siglos XVI-XVII, vol. II, Barcelona, 1985. págs. 55-56, Rodriguez Aleman. I. El puerto de Málaga bajo los Austrias. Málaga, 1984, pág. 106, ColAO, A., Cartagena en los siglos XVI y XVII. Murcia 1982, pág. 26. GarCiA MARTINEZ, S., Bandolerismo, pirateria y control de moriscos en Valencia durante el reinado de Felipe II, Valencia, 1977. Catala I RocA, P., De cara a la Mediterrania. Les torres del litoral català, Barcelona, 1987; VINCENT, B., Andalucia en la Edad Moderna, Economía y sociedad, Granada, 1985; Pérez de Colosia Rodriguez, M. I., "Importancia estratégica de Málaga en el Mediterráneo Occidental durante el siglo XVl', en España y el Norte de África. Actas del Primer Congreso Hispano-Africano de las culturas mediterráneas "Fernando de los Rios Urruti". Granada, 1987, pág. 353. PEREIRO, P., Vida cotidiana y élite local; Málaga a mediados el Siglo de Oro, Málaga, 1987, pág. 60. Gamir Sandoval, A., (1988), pág. 160. Archivo General de Simanca (AGS), Guerra Antigua, leg. 217, f. 45.

“ Gonzalez Davila, G., Teatro de las grandezas de la Villa de Madrid, Madrid, 1623, f. 252.

5 AGS, Guerra Antigua, leg. 247, f. 159, 160 y 247. 
dado el carácter de éstas, la mejor manera de defenderse no era abortándolas en el mar como en el caso citado, pues resultaba bastante difícil controlar todos los lugares por los que el enemigo podía aproximarse, sino procurar defenderse de ellas mediante la fortificación de la costa con un sistema de fortalezas del que forman parte las torres, cerrando así el territorio - como escribía Antonelii- con una suerte de muralla imaginaria de la que los vigias eran las torres. Fueron obras hechas para una "guerra defensiva a la qual tiene respecto el fortificar", una guerra que "pretende escusar daño como la offensiva alcançar provecho" 6 .

Sobre la arquitectura de estas torres, ésta será tratada en cada una de las áreas en que se dividió la costa para las actuaciones de la monarquía en función del reino a que pertenecian, pues a pesar de las evidentes similitudes, hay variaciones según el ingeniero autor de la traza que a modo de patrón se siguió en cada una de las costas. Hay de todos modos unas consideraciones previas, como son el hecho de que los cambios en la artillería, que fueron determinantes a su vez de un cambio radical en las fortificaciones, afectaron también a las torres, pues en el siglo XVI, se redujo la altura (en la medida en que eso se puede hacer en una «torre») para hacerlas menos vulnerables a las trayectorias de la nueva artillería, se hicieron con un escarpe que podia afectar sólo a la base maciza o a toda la torre y se reforzaron también en su interior para poder soportar las piezas de artillería que muchas de ellas tuvieron. Cilindricas, cuadradas y en raros casos poligonales en planta fueron unas obras puramente funcionales, en las que resulta dificil encontrar significados que excedan lo que fue su función de vigilancia. La mayoria de ellas se levantaron sobre una base o plinto, sobre el cual se asentaba el primer cuerpo macizo de la torre, sobre éste la puerta a la que se accedía por escalas que podian ser retiradas, y una vez en el interior una o dos estancias abovedadas, con una escalera de caracol total o parcialmente embutida en el muro para acceder a lo alto, a la plataforma superior que se complica más o menos según la artillería que deba tener. Hubo torres más o menos fuertes, asi como hubo diferencias entre las que trazaron unos ingenieros $u$ otros a lo largo del siglo; de esas y otras diferencias se tratará más adelante, para subrayar ahora únicamente el carácter estrictamente funcional que tuvieron.

Sólo cuando se trató de torres concebidas como fuertes, tal como las trazas para dos torres en La Goleta en 1557 (son en realidad para

${ }^{6}$ Informe de Vespasiano Gonzaga sobre las torres de la costa del reino de Murcia, 3 de agosto de 1570. AGS, GA, leg. 177 , f. 31. 
una sola torre, que se dice que puede ser también cuadrada y con casamatas en las esquinas, destinada a guardar el agua de los pozos) (fig. 1) o las de los Alfaques en 1580-81 (a las que nos referiremos en el epigrafe dedicado a la costa de Cataluna), es posible imaginar para las primeras un simbolismo latente en sus formas estrelladas, y rastrear para las segundas su relación con otras formas abaluartadas más complejas y perfectamente codificadas por los tratados de arquitectura militar. También las poligonales (hexagonales) que propusieron Vespasiano Gonzaga y el ingeniero Antonelli para la costa de Murcia, nos pueden llevar a buscar alguna clave más allá de la comodidad y funcionalidad — que son sin embargo los argumentos que se dan en los informes - para la traza de estas torres. Se hace difícil de todas formas admitir a priori un simbolismo tanto para esas torres poligonales como para las circulares y cuadradas que se construyeron en las costas del sudeste peninsular, a pesar de sus plantas de formas perfectas como el círculo y el cuadrado. El carácter funcional de esta arquitectura contribuye a su interés, pues tampoco hay que olvidar que las trazas se deben normalmente a importantes ingenieros, que en estas obras menores plasmaron sus conocimientos y experiencias para servir a un gran proyecto que hay que entender en relación con lo que fue el control y defensa del terriotorio.

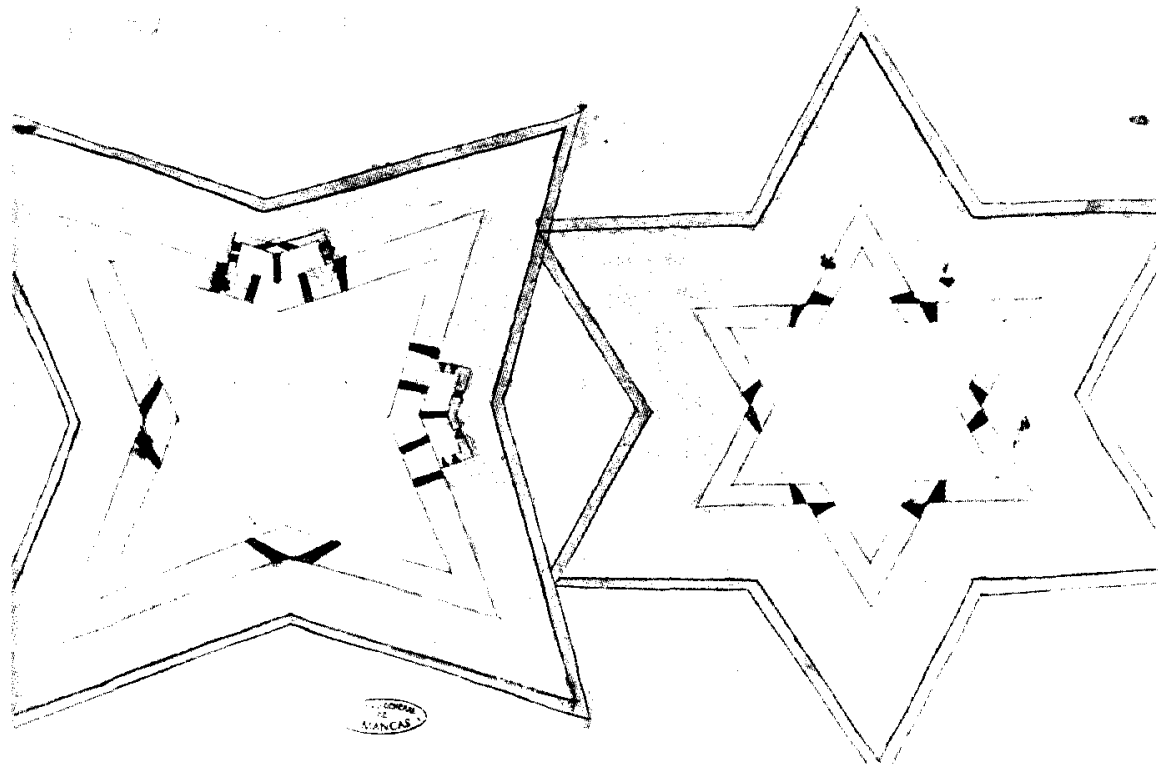

Fig. 1. Torres fuertes para La Goleta. Archivo General de Simancas. 
La cantidad de topónimos existentes hoy en las costas mediterráneas que se basan en la palabra "torre"; la serie de pueblos levantinos que, retirados al interior, sólo habitaron la costa al desaparecer el peligro muchisimo tiempo después de este siglo XVI y que por cierto conservan hoy la denominación de "pueblo" para el que está en el interior, llamando "playa» al que está en la costa; la frase coloquial de "moros en la costa", son algunos datos tomados del presente que nos recuerdan la envergadura de un proyecto que articuló en un mismo sistema defensivo las costas de los distintos reinos peninsulares.

Dado que a quien beneficiaban las torres fundamentalmente era a quienes vivian en las tierras costeras, lo normal fue que su financiación (tanto construcción y mantenimiento como guardas) corriera a cargo de los que vivian en esas tierras, teniendo que pagar los moriscos o cristianos nuevos un impuesto especial para la defensa de la costa; los municipios y los grandes señores como el Duque de Medina Sidonia se encargaban de las torres que se encontraban en su jurisdicción. Ya en el reinado de Felipe II, y en el caso concreto de las torres de la costa de Andalucía, se pidió en varias ocasiones que la ciudad de Sevilla contribuyera al gasto puesto que se beneficiaba de la protección que suponian tanto para el comercio como para la pesca que abastecia a la ciudad. En Valencia se utilizó el impuesto sobre la seda para las torres. En definitiva, todo aquel que se beneficiaba habia de contribuir a la financiación de las torres que los representantes del monarca decidieran que era preciso hacer o reparar, pues era el Consejo de Guerra, una vez informado de las distintas situaciones, el que tomaba las resoluciones en consulta con el rey Felipe II. Tanto es asi que, previendo la posible oposición de los pueblos que iban a tener que pagar las torres del reino de Murcia, proponía Vespasiano Gonzaga en 1570 no hacer tantas como queria Antonelli, sino menos porque «en semejantes negoçios no es bien asombrar los pueblos de una vez mas yrlos engañando en su provecho, poco a poco de manera que no se espanten de primera vez". En beneficio propio esos pueblos debian financiar las torres que les iban a defender, pero siguiendo puntualmente las instrucciones que en cuanto a ubicación, trazas, materiales, etc. dieran los representantes del rey que controlaban además la correcta ejecución de todos esos puntos, consiguiendo de esta forma que la defensa que las torres podian proporcionar fuera lo más efectiva posible?

AGS, GA, leg. 177. f. 31 y leg. 208. f. 57 y 281. Sobre financiacion de las torres. ademas de la mayoria de los documentos que citamos en estas notas, pues el coste de la obras, las dificultades de recaudar el dinero y quien debra pagarlas son los temas que 


\section{LA COSTA DE ANDALUCIA}

La costa de Andalucia, que era como se llamaba a lo comprendido entre la frontera con Portugal y Gibraltar, desde la torre de Pino Seco en Ayamonte hasta la torre de la Chullera en Gibraltar, fue protegida por cuarenta y cinco torres, financiadas unas por las ciudades, otras por los señores y otras por el rey. De ellas, diecinueve ya existían cuando el rey Felipe II envió a D. Frances de Álava, Capitán General de Artillería, a visitar la costa; en una relación del año 1576 se dice que debia ir Luis Bravo de Lagunas llevando consigo al ingeniero Antonelli, y que debian procurar que las nuevas torres, si se hacian en lugares de señorio, fueran financiadas a medias por los señores y los vecinos $y$, si se hacian en tierras del rey fuesen financiadas también a medias por éste y los lugares en cuyo término se ubicaran. En una consulta del Consejo de 31 de julio de 1608 en la que se informa sobre la construcción de estas torres a lo largo de 26 años, se dice que las cuatro del término de Gibraltar fueron a costa del rey, tres en el término de Tarifa a costa del Duque de Alcalá, una en el término del Puerto de Santa María a costa del Duque de Medinaceli y tan sólo de una, en el término de "Vegel", se dice que fue a medias entre el Duque de Medina Sidonia y la villa, asi como tampoco se hace alusión a la participación de los lugares en la financiación de las que se comenzaron desde 1585 a 1588 . Ese año se pararon las obras (no debieron ser todas, a pesar de lo que se dice en esta consulta, pues en ese año precisamente fue enviado el ingeniero Livadote a ocuparse de las torres de la costa de Andalucia) hasta el de 1595, pero incluso en el año que se hace consulta quedaban varias por acabar y estaban sin guarda ni artillería, lo cual era muy perjudicial, como lo demostraba el hecho de que ese año se hubieran llevado cautivas a cincuenta personas de esa costa.

Para las torres de esta costa señaló sitio en principio Vespasiano Gonzaga (en 1616 se dice que de eso "ha mas de cuarenta años"), pero fue con D. Frances de Álava y el comendador Luis Bravo de Lagunas

\footnotetext{
normalmente se tratan, habiendo que rastrear entre todos esos datos los que se refieren a quienes y cómo las construyeron. se pueden consultar también: OLESA MUNIDO, F.F., La organización naval de los Estados Mediterráneos y en especial de España durante los siglos XVI y XVII, Madrid, 1968, pág. 966 y ss. GamIR SANDOVAL, obra citada, (1988). MORA Figueroa, L., Torres de almenara de la costa de Huelva, Huelva 1981. Vera Delgado. A.M., La última trontera medieval: la defensa costera en el Obispado de Málaga en tiempos de los Reyes Católicos, Malaga, 1986.
} 
con los que el proyecto de articular en un sistema de torres efectivo la defensa costera tomó cuerpo. En 1576 parece que se envió a la costa de Andalucía al ingeniero Antonelli con Luis Bravo de Lagunas, pero nada se dice de Gonzaga. Tampoco queda clara la participación de Antonelli, pues en 1577 escribió Bravo de Lagunas al rey acerca de las fortificaciones de la costa indicando que se dirigía al Puerto de Santa María a esperar al maestro mayor de las obras del reino de Granada, a quien el rey había ordenado ir alli "a hacer las plantas de las torres que se han de hacer". Desde el año anterior el Consejo se hallaba a la espera de que trajera la relación de las torres "un cavallero a quien su Magestad mandó vaya a designarlas y conçertarlas", refiriéndose probablemente a Bravo de Lagunas. Quien llevó la relación a la corte fue Luis de Montalvan, que fue uno de los que reconocieron la costa, y a quien Luis Bravo de Lagunas, cuando propuso las torres que se habían de hacer "en Sanlucar y en las Arenas Gordas y Rio del Oro", se refería como "hombre platico y maestro de cantería", que le había recomendado también el conde de Barajas en Sevilla por "la mucha avilidad que tenía en lo que toca a esto de torres y otras cosas semejantes".

Entre papeles del año 1583 en el Archivo de Simancas, aunque se ha indicado que podrían datar del año 1577 , coincidiendo con los primeros informes de Bravo de Lagunas, se encuentran dos importantes informes: una «Relación de las torres que paresce haber menester en la costa desde Santlucar hasta el cabo de Santa Maria que es a poniente de Faro", así como otra "Relación de las torres que paresce aver menester desde el fin del estrecho la buelta de Poniente» (Fig. 2). En estas relaciones se representa en el margen la forma que han de tener las torres, que diferencia su autor entre "ordinarias", que serian las tradicionales torres almenaras, y "buenas", que son las que deben de llevar artillería, siendo éstas de dos cuerpos y más grandes (Fig. 2 bis). Disenadas tal como se dice en la misma relación por el «maestro mayor de las obras de Cádiz y Puente de çuaço", eso nos puede hacer pensar en Juan Marín, pues sus trazas para las torres grandes y pequeñas de la costa de Sanlúcar de Barrameda que datan del mismo año de 1583 acompañan dicha relación (Fig. 3 y 4), pero es posible que se basara en los informes del ingeniero italiano Juan Pedro Livadote, que en un memorial en el que detallaba todos sus servicios a la monarquia española incluia (sin indicar la fecha) el haber recorrido con gran riesgo para su persona la costa del Algarve por orden que le habia dado el duque de Medina en Ayamonte; lo único que parece deducirse del memorial es que dicha visita se produjo después de que don Frances de Alava y Luis Bravo de Lagunas reconocieran la costa de Andalucia, habiendo sido consultado también Livadote en esa ocasión. El hecho de que se inclu- 
F I A C I ON delas torres queparsec auermenelfer enla fortadesde Sant Cura, Salta el cabo de Santra Mlana quees aponente de Faro.

Sa carbonera. Di sant lucar ala carbonera guees rna oenta. ay tres lequas yay , aguadeposos en afundancia: V Los nawos delosenempgos acuidion alli muchas vefes yparesce autermencter vnatorre Ordinaria porque seva de muisoprouecso, co inticra detaluque demedina sidonia-

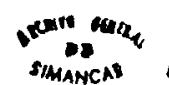

Dela carbonera ala Hiquera av dos Jeguas:

yenel camino noay agua

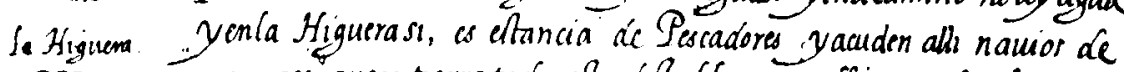
EP enemgos guces ticrra toda efta disfoblaxa:- yalli guardan los nauios que vienen de Sant fucar y van alla, Ianese gue a ya torre ordinaua Is delmispo Dugues

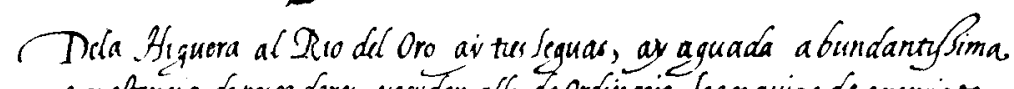

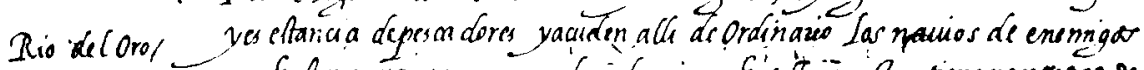

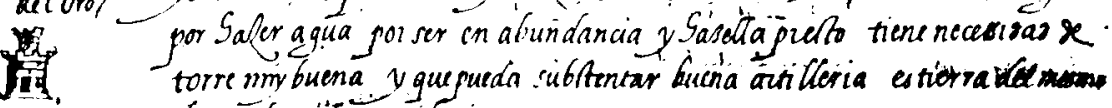
duquédemidina sidonia.,

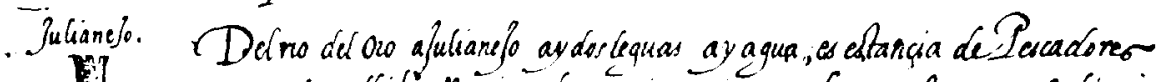
II yaciden alli los naumos de enemigos siempre, Sameneiter torre Ordinaza De Julianexo alabarra de saltes ures fa de Guelua ay ma gran cegua Barmdelalses. a gue esmoneter my fuena torre con min burta Aztilleria, porque en

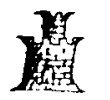
Una lequa delres es tode desforlado y tordé pueden eftar muchorna

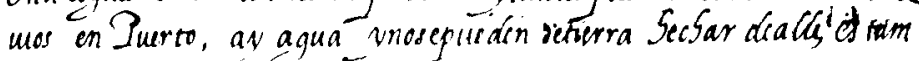
bien terra reemesmo Dugue -

Detta barra ala funta de Mala ques ala entrada de Guelua y palos ay La

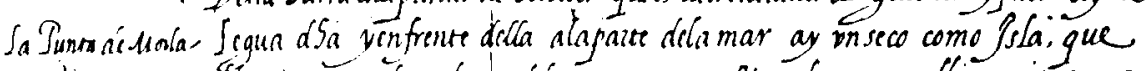

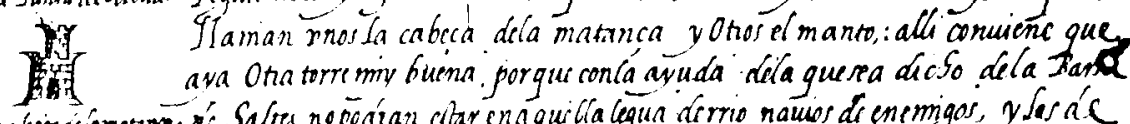

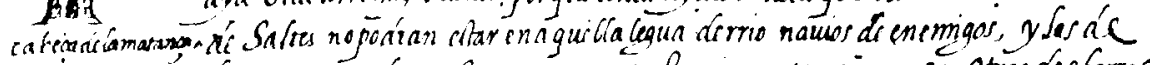

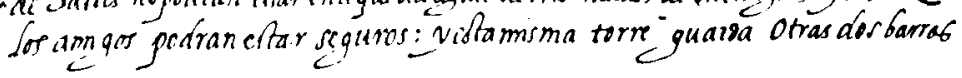

Fig. 2. "Relación de las torres...". Costa de Andalucía. Archivo General de Simancas. 


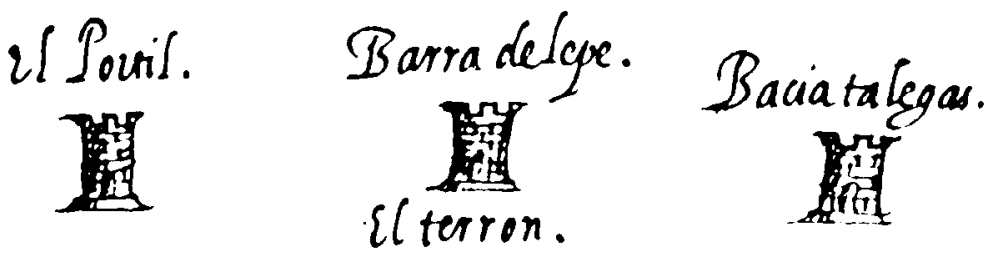

Cabesa Scca.
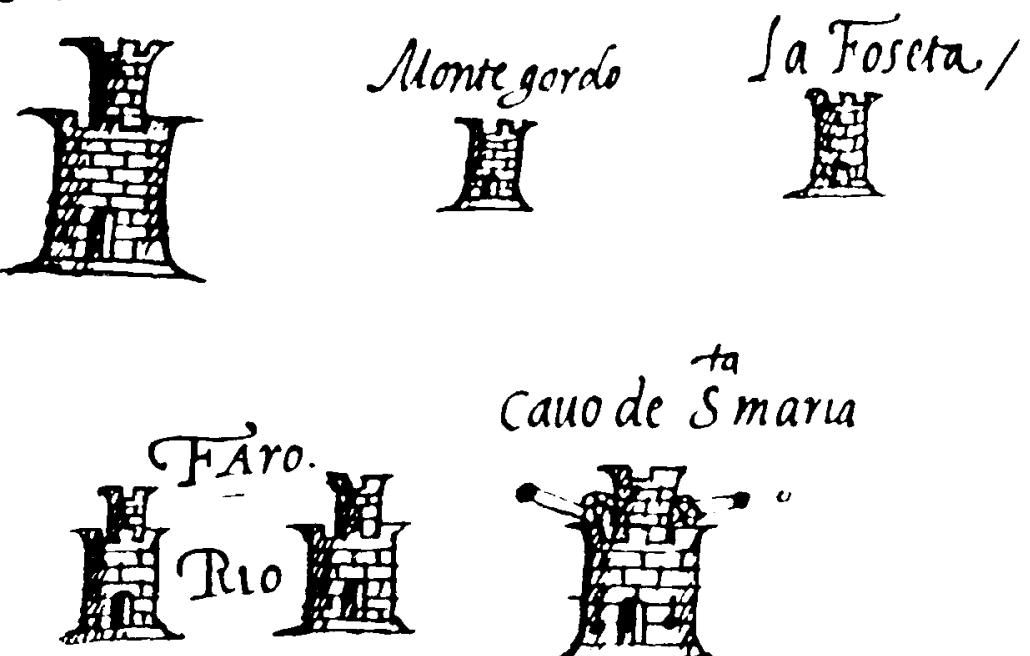

Cauo de Ŝ Smaria
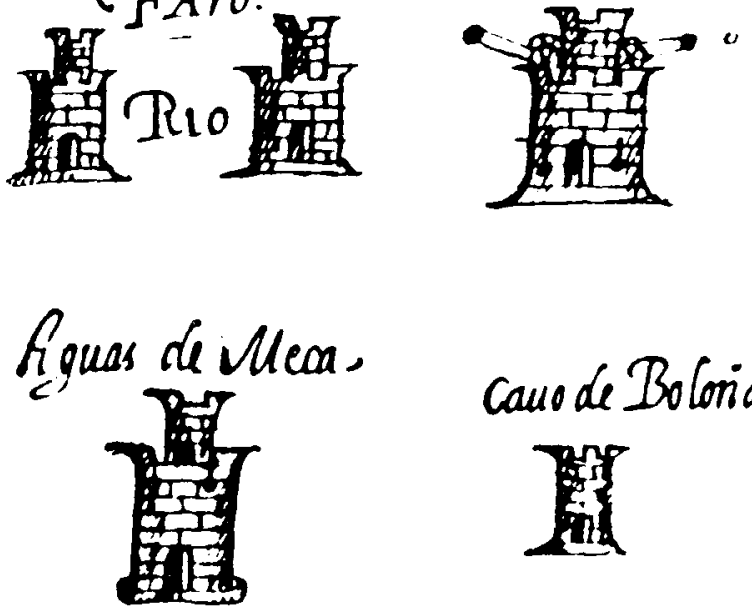

Fig. 2. (bis). "Relación de las torres...". Resto de las torres que aparecen en la Relación. Archivo General de Simancas. 


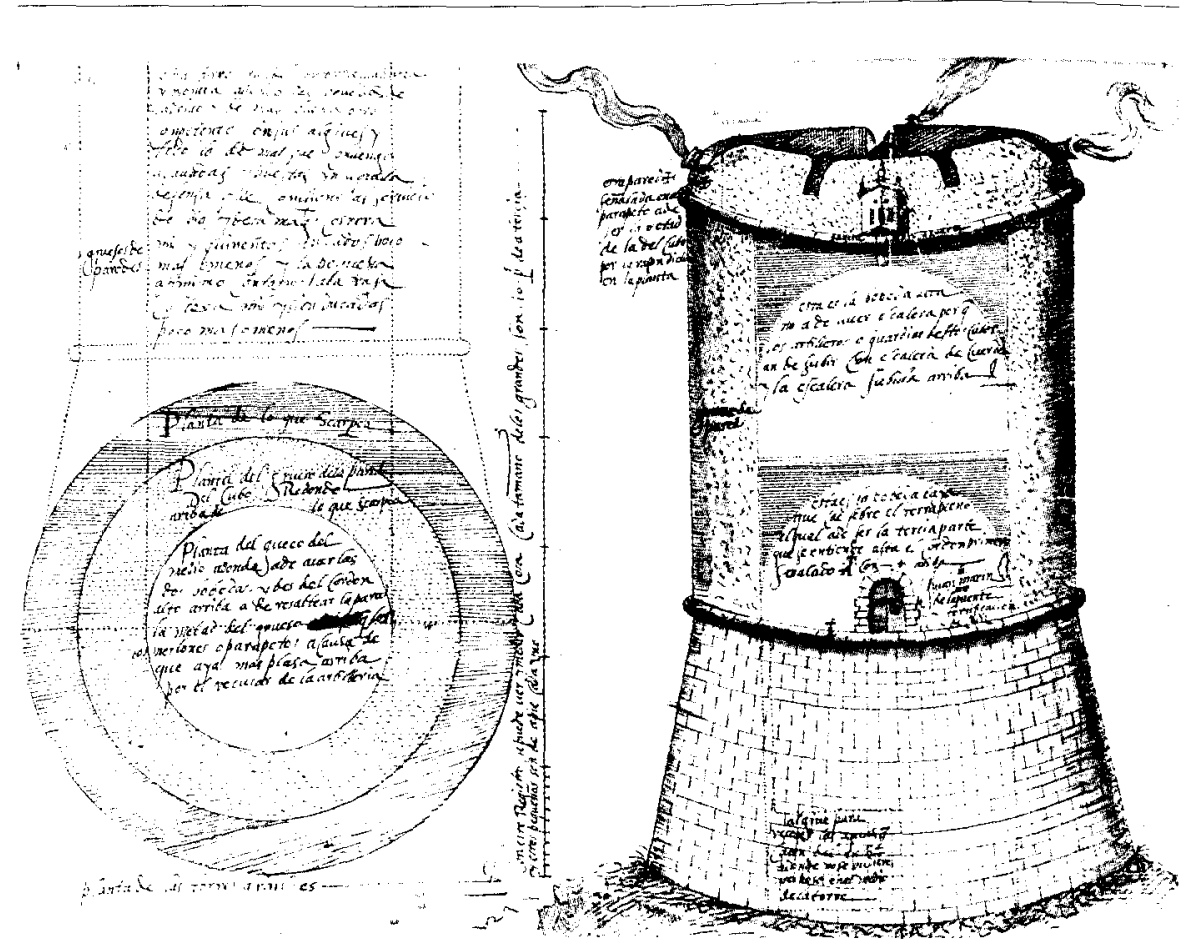

Fig. 3. Traza para las torres grandes de la costa de Sanlucar de Barrameda. por Juan Marin. Archivo General de Simancas.

yan en la relación torres como la de Faro o el cabo de Santa Maria. que se encuentran en Portugal. puede hacernos pensar en la información que aportaria Livadote como fruto de su visita a esa costa.

Las torres que propuso Luis Bravo de Lagunas fueron al parecer muy fuertes. y hubo opiniones en contra de que se hicieran unas torres tan fuertes. En ese sentido se expresaba don Diego Maldonado el mismo año 1577: consideraba que puesto que esa costa era distinta a otras. sobre todo en la playa de "Arenas Gordas", las torres con artilieria estarian a merced del enemigo, pues ellas solas no se podrian defender, además de ser zona de dunas que por su movilidad haria muy dificil la construcción; propone que se debian hacer torres como las del reino de Napoles, en las que hubiera tan solo tres o cuatro hombres que dieran aviso del peligro con señales y después huyeran en caso de que el enemigo se acercara. Cuando todavia esto se estaba dilucidando recomendó el Consejo que para el fundamento de las torres que habia que hacer en Murcia, se enviara alli "un traslado de la condiçion que acerca desto trata, en las condiçiones quel conde de barajas, embio, de las 


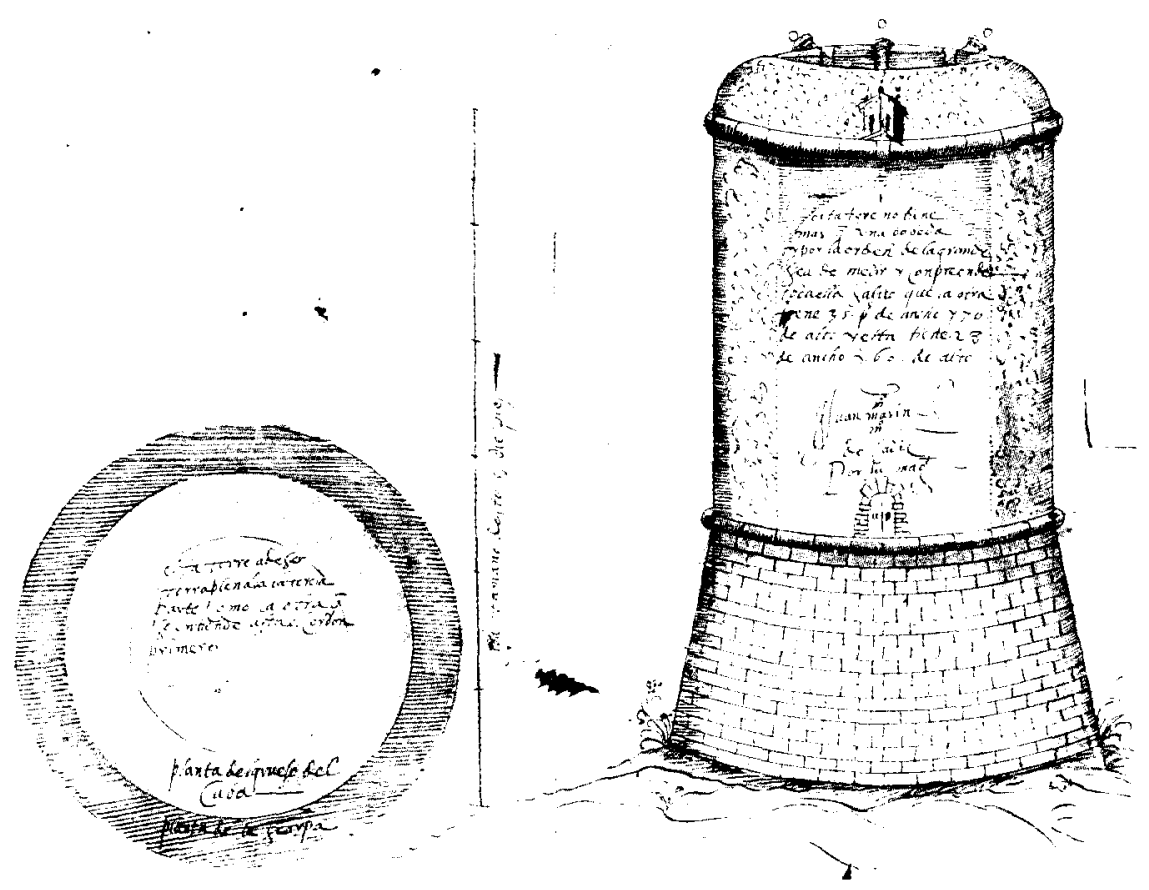

Fig. 4. Traza para las torres pequenas de la costa de Sanlucar de Barrameda. por Juan Marin. Archivo General de Simancas.

torres del andaluzia". pero a esto contestó el corregidor de Murcia que no servian esas condiciones, al no tener las torres de Andalucia "grosor y capacidad" para artilleria, to cual nos hace dudar sobre si el informe del conde Barajas coincidia con la propuesta de Bravo de Lagunas, pues desde Murcia se dice que son torres poco fuertes para la artillería (¿desconocimiento?) y Maldonado en cambio las considera excesivamente fuertes.

La dificultad de construcción era un hecho, pues al mismo Bravo de Lagunas le informaron "architectos y personas de ingenio" que en concreto la torre y fuerte de Modolón en el término de Sanlúcar era muy difícil de hacer debido a la arena y a las olas que complicarian su cimentación, y por su parte la villa informó de que para ella dicho edificio no tendria ninguna utilidad pues quedaba demasiado lejos para que su artillería alcanzara a los navios que entraban, y demasiado lejos también (en la otra parte del rio) como para poder llegar a socorrerla desde la villa en caso de que fuera atacada. A pesar de ello Bravo de Lagunas insistió en la necesidad de esa construcción, para la cual dio la traza Juan Am- 
brosio Maigrat, ingeniero; años más tarde, en 1613, el ingeniero Cristóbal de Rojas aconsejaba sobre un modelo conveniente para ser hecho en la punta de Modolón, así que, si bien no queda claro en que momento se hizo, el caso es que en el año 1618, cuando Cristóbal Mesía Bocanegra dio un informe del estado de las torres, pudo decir de esta de Modolón que "es muy buena, y fuerte».

Como ya hemos visto la construcción de las torres tardó en ponerse en marcha. Montalbán siguio vinculado a ellas, encargado de su construcción, tal como sabemos por un informe de D. Frances de Álava sobre lo necesario para los fuertes del estrecho de Magallanes en 1581, en el que proponía que las trazas que diera el ingeniero Fratín (aunque no fue él quien finalmente los trazó), las ejecutaran «un montalvan que reside en Sevilla y un Juan cornejo en Gibraltar, a quienes se a encomendado la esecuçion de las torres de la costa de andaluzia". Desde diciembre de 1586 Montalbán ${ }^{8}$ se ocupó como ingeniero en la fábrica de las torres de la costa de Andalucia, a pesar de que su casa la tenia en Madrid. El 13 de mayo de 1588, y ante la demanda de uun ingeniero platico de semejantes obras que assista a la fabrica", el Consejo de Guerra informaba que se estaba ocupando de ellas Montalbán, que era «maestro mayor de edificios de agua" del rey, con dos ducados de salario al día. Por hallarse Montalbán muy enfermo, opinaba el Consejo que debería ir otro ingeniero "platico" con buena salud, y es cuando decidieron enviar a Juan Pedro Livadote, que estaba también propuesto para ir a la costa de Granada.

Este fue al parecer el ingeniero (a Antonelli no le hemos vuelto a ver citado) que colaboró con D. Frances de Álava y Luis Bravo de Lagunas cuando visitaron la costa de Andalucia, pues fue el «que hizo las trazas y mediciones de las torres que se debían hazer de Gibraltar a Ayamonte formando una pintura de la costa y torres y lo puso en lienzo y en papel general». Desgraciadamente no conocemos hoy tal documento gráfico. que hubiera sido clave al tratarse, además, de un ingeniero al que en

"Con respecto a este Montalban se nos plantean dudas. ya que en unos documentos se le llama Luis y en otros Francisco. pero coincide la ida de "Luis" a la corte a llevar el informe en 1576 con que a "Francisco" le nombren "maestro mayor de fuentes y encañados" en El Escorial. en cambio no coincide el que en 1581 se hable de el como residente en Sevilla con los trabajos que se atribuyen a Francisco de Montalban en El Escorial esos años, siendo de nombre "Francisco" el "maestro mayor de edificios de agua" del rey y el que se queja de estar destinado en Andalucia a pesar de tener casa en Madrid. Hasta que nuevos documentos o datos que ahora desconozco aclaren si puede tratarse de la misma persona, consideramos necesaria esta nota aclaratoria. Sobre Francisco de Montalban y sus trabajos en El Escorial. vease: GaRcIA. TAPIA. N.. Ingenieria y arquitectura en el Renacimiento español. Valladolid, 1990. 
1587 se le van a encargar las torres de la costa de Granada por fallecimiento de Ambrosio Malgrat (que como vimos anteriormente tambien intervino en las de la costa andaluza) y, aunque Livadote no se llegara a ocupar de las de Granada, se le puede suponer en ese momento como un ingeniero especializado en torres.

El ingeniero Juan Pedro Livadote es uno de esos técnicos que, sin llegar a la fama de los Antonelli, Fratín o Spannocchi, desempeño una serie de labores de importancia al servicio de la monarquia española que debemos detallar aquí por ser un ejemplo de la variedad de funciones que un ingeniero podia tener. Habia trabajado en Nápoles, tanto en las fortificaciones como en los caminos de ese reino en tiempo del virrey marqués de Tarifa, se ocupó despues de la fortificacion del Peñón de Velez con el ingeniero Agustín Amodeo y acabó recalando en la corte ocupándose alli de allanar el sitio de las caballerizas, derribó la torre de la puerta de Balnadu y la del juego de pelota cy la fábrica de dha puerta y hazerla alcantarilla y los dos paredones y el que esta debaxo de palacio donde va a fenecer la alcantarillas de palacio y de la Villa". Uno de sus principales méritos fue al parecer el haber propuesto que todas estas obras - asi como la acequia de Aranjuez - se hicieran a destajo y no por jornal con lo cual se abarataron los costes. Se ocupó también de derribar una torre en Ocaña que se había caido parcialmente y se embarcó camino de América para hacerse cargo de las fortificaciones "desde la florida a mexico» pero sólo llegó hasta Canarias, regresando a Sanlúcar. Aconsejó a don Frances de Álava y Luis Bravo de Lagunas sobre las fortificaciones de la costa de Andalucia, reconoció la costa del Algarve haciendo trazas de ello. estuvo de ingeniero en Gibraltar, reconoció parte de la costa de África y acabó. tal como hemos visto, al cargo de las torres de la costa de Andalucia en 1588, lo cual tuvo además dificultades añadidas, al existir problemas de financiación pues las villas que tenian que contribuir a la construcción se habían quejado de que la tasación de ellas era mucho más alta de la que en su momento hizo Luis Bravo de Lagunas.

Livadote se ocupó pues, desde 1588, sustituyendo a Montalbán, de "mirar q se hagan bien hechas" las torres de la costa de Andalucia. y el 8 de octubre de ese año llegó a Gribraltar con ese fin. En el término de Gibraltar tenía que ocuparse de tres torres, la del Rocadillo, la de entre los dos ríos y la de Fontanillas, pero además había que reedificar. según informa el corregidor. la torrecilla de San Garcia en el "playazo de zetares" para que los labradores y gentes del campo pudieran refugiarse en ella cuando llegaran los moros, también habia que ocuparse de la "torrenueva" en la zona de levante (ya hacia el reino de Granada). pues aunque se hizo en 1580, seguia sin guardas lo que era un peligro ya quelos moros se escondian debajo de la misma torre saliendo al camino sin 
poder ser descubiertos. Con respecto a otras torres de la costa, Livadote informó el 2 de junio de 1589, que la de Santa Catalina junto al Puerto de Santa Maria se acabaria en ocho dias (en realidad en julio el adelantado de Castilla informaba que estaba sin solar y sin pretil que protegiera a la artillería), y que la de la isla de Tarifa estaba ya acabada.

Las dificultades para construir estas torres no fueron sólo económicas y de cimentación, sino que, por ejemplo, de la torre del Asperillo en la playa de Arenas Gordas se sabe que a comienzos del XVII estaba sin acabar debido a que se había caido cuando se estaba haciendo y los moros se llevaron a la gente, asi que el peligro corsario afectó también a lo que fue la propia construcción de las torres. De 1616 y 1618 se conservan sendas relaciones del estado de las torres, que vamos a resumir ahora: la de Pino Seco en la barra de Ayamonte estaba acabada y era buena torre, con cinco pies más de alto incluso de lo que era obligación; en el término de Lepe existían la torre de Sierra Bermeja. que aunque vieja se había arreglado, y la del Terroro; en el término de Gibraleón estaban la torre de Marijata y la de la Punta de Umbría; las torres de la punta de la Arenilla, Morla, Río de Oro, Asperillo, Higuera, Carbonera, Cruz de Salabar y Modolon estaban en la playa de Arenas Gordas (términos de Palos y Almonte); a continuación la torre de Santa Catalina en el Puerto de Santa María, y en el térnino de Cádiz las de San Sebastián, Hércules, Campanilla, e isla de Santi Petri; en el término de Chiclana la torre Bermeja y la torre Barrosa, en el termino de Conil la torre de Aroche que era vieja como la del Conilejo y la de Meca, que estaban en el término de Vejer junto con la de la Tembladera, que en cambio era nueva y bien acabada. En Tarifa existian la torre del cabo de enmedio, la de la Peña (o del Barranco), la de la isla de Tarifa y la de Guadamecil, y en Gibraltar la de las Fontanillas, la de la Punta del Carnero, San Garcia, del Almirante, de entre los dos ríos, Rocadillo, torre nueva (entre estas dos últimas la relación de 1616 cita la de Mayorgas y la de los Diablos). Carbonera, Guadiaro y Chullera. El sistema defensivo que formaban todas estas torres se apoyaba también en los castillos de Cartaya, Chipiona, Rota, Conil y Barbate. Si a ello añadimos las importantes fortificaciones de la ciudad de Cádiz y de Gibraltar tendremos una visión general de lo que fue la defensa de esa costa en el reinado de Felipe II.

Por lo que se refiere a la arquitectura de estas torres, no todas fueron trazadas por Malgrat y, sobre todo, Livadote, pues, por ejemplo, sobre la torre que había que hacer en 1578 en el término de Cádiz "y lo demas" se pidió parecer al ingeniero Fratín (Jacome Palearo Fratín), pero se decidió -basándose en la relación que había dado Luis Bravo de Lagunas de las torres de Andalucía- que la torre para guardar en el 
puente de Zuazo la entrada de las galeras no debia ser tan fuerte como la habia trazado Fratin, sino de treinta y cinco pies de diametro y sesenta de alto, la tercera parte terraplenada y con dos bóvedas, con tres guardas y un artillero. Sobre las otras torres el Fratín no informó pues no hizo la visita, decidiéndose que cuando volviera de Navarra hiciera el informa sobre dichas torres. Coincide la descripción que se da de esa torre de Cádiz con lo que propuso el maestro mayor del puente de Zuazo y fortificación de Cádiz, Juan Marín (de familia de ingenieros venecianos), para las torres de la costa. Sería una de las torres grandes (Fig. 3), aunque su altura fuera de sesenta pies, como las torres pequeñas (Fig. 4), y no como las grandes que habian de tener setenta. En estas trazas a escala queda perfectamente claro el proyecto de Juan Marín (que como ya se ha dicho, se encuentra entre papeles del año 1583, aunque pueda ser anterior): las torres pequeñas con una sola bóveda, de veintitrés pies de ancho y sesenta de alto, y las grandes con dos bóvedas, treinta y cinco pies de ancho y setenta de alto, con algibe para el agua, y con fuerte parapeto para la artillería; tanto unas como otras debian ir terraplenadas hasta un tercio de su altura.

En realidad el proyecto de Juan Marín no se ve reflejado ni en los restos que se conservan de las torres (Fig. 5), que más parecen seguir los proyectos de 1577, ni en una relación del año 1616 en que se dice la forma en que estaban construidas las torres artilladas de la costa de Andalucia. En 1577, en varias instrucciones que se conservan, se decia que habian de ser redondas, de treinta y cuatro pies de ancho, y asentadas sobre una base de treinta y ocho pies que sobresaliera dos pies del suelo, debian tener cuarenta y siete pies de alto, con una parte maciza hasta los dieciocho pies, y encima dos estancias abovedadas, una encima de otra; las torres debian ser ligeramente escarpadas en su totalidad, y no sólo en un tercio de su altura, de manera que en su parte superior el diámetro fuera de treinta pies; en lo alto debian llevar un parapeto para la artilleria, debían tener escaleras en el interior (en cambio en la traza de Marín no hay escalera pues esta debía ser de cuerda), una ventana en la estancia superior que diera hacia el mar, una chimenea en el mismo aposento, y la puerta de madera forrada de hierro y con tranca en la estancia inferior. En el informe que dio el secretario de la fábrica de las torres de Cádiz en 1616 hablaba de torres más grandes, con cuarenta y cuatro pies de diámetro y cincuenta y cinco pies de alto, siendo maciza hasta los veinte pies, pero también se trataba de torres con una ligera escarpa, quedando en la parte de arriba con treinta y ocho pies de diametro, se refería a la estancia con bóveda, a una escalera de caracol y a la consabida puerta de madera chapada en hierro y con trancas. Las torres del Rocadillo y de Entre Rios. que son dos de las que se tenía que ocupar Livadote cunado fue a Gibraltar 


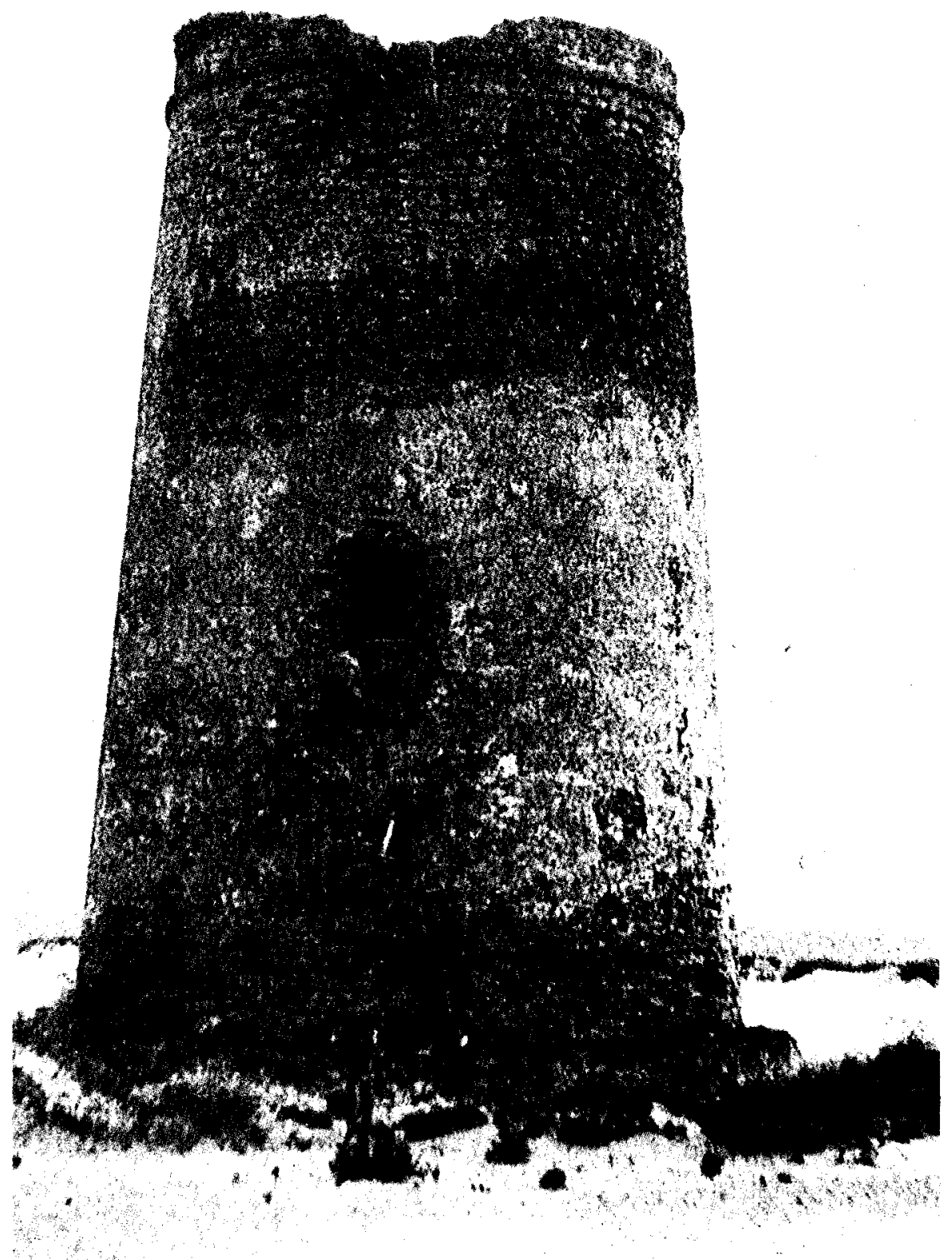

Fig. 5. Torre de la Carbonera. Costa de Andalucia. (Tomada de Mora Figueroa). 
en 1588. son en cambio de planta cuadrada, troncopiramidales. llevan ladroneras en los cuatro lados de la torre, y se levantan sobre una base o plinto; a pesar de que no tienen las mismas medidas, ambas fueron trazadas, sin duda, por la misma mano.

Entre los proyectos de 1577 y el de 1616 se encuentra la propuesta de Cristóbal de Rojas para las torres de esta costa el año 1613. Al ser uno de los más importantes ingenieros españoles de su tiempo, profesor en la Academia de Matematicas de Madrid, viajero fuera de España para formarse como ingeniero, y autor de libros fundamentales sobre fortificación, resulta de un especial interés lo que Rojas. que se ocupaba de las fortificaciones de Cadiz y Gibraltar, opinaba acerca de las torres. Ademas de su informe dio tres trazas; en el informe se quejaba de la presencia en Cádiz de un letrado, el licenciado Fuente Hurtado, a quien se habian encargado las torres de la costa, y que no sólo tenia un sueldo de mil trescientos ducados al año, sino que, además. habia nombrado a un maestro mayor en Sevilla con quinientos ducados al año «no siendo soldado ni ingeniero, ni en su vida había visto torre en la mar», nombrando también como veedores de las torres "a hombres que jamas vieron fábricas": ante lo que le parecia un disparate recomendaba que todo ese dinero se empleara en la construcción de las torres. y que se nombrara a un ingeniero practico y a dos maestros "que sepan apreciar bien la obra y materiales de alli». El maestre de campo de Cádiz, Don Fernando de Anasco, se muestra de acuerdo con Rojas, y el Consejo de Guerra opina que alguien rombrado por "el de Justicia" (era el caso del licenciado) puede ir a cobrar los repartimientos. pero que todas las decisiones acerca de las torres. Su ubicación. su forma. etc. las debe tomar el Consejo de Guerra. con lo cual Rojas y Añasco consiguen que las cosas vuelvan a su cauce normal. A pesar de situarnos ya en el siglo XVII. hemos reflejado este conflicto debido a que en el se muestra cómo se habia consolidado un sistema de trabajo que databa de tiempo de Felipe Il; un militar (Añasco). un ingeniero (Rojas), un maestro mayor. un aparejador. un veedor. un pagador y tenedor de herramientas, y algunos sobrestantes, eran el equipo que trabajaba en las fabricas de la costa con sueldos pagados por la monarquía.

Cristóbal de Rojas proponia unas torres (Fig. 6) redondas. pero a plomo y no escarpadas (con lo cual estaba de acuerdo Añasco), y con una "guirnalda" o parapeto en la parte superior que protegiera al soldado de guardia. Por no ser escarpadas se podrian tirar piedras desde lo alto a los enemigos sin dañar el cimiento de la torre. Además de esta propuesta de torre redonda para vigilancia y, como estaba pensando - además de la torre de Modolón- en la de San Sebastián en Cádiz. recomendaba que en ella no se encendiera nunca una luz (lo contrario 

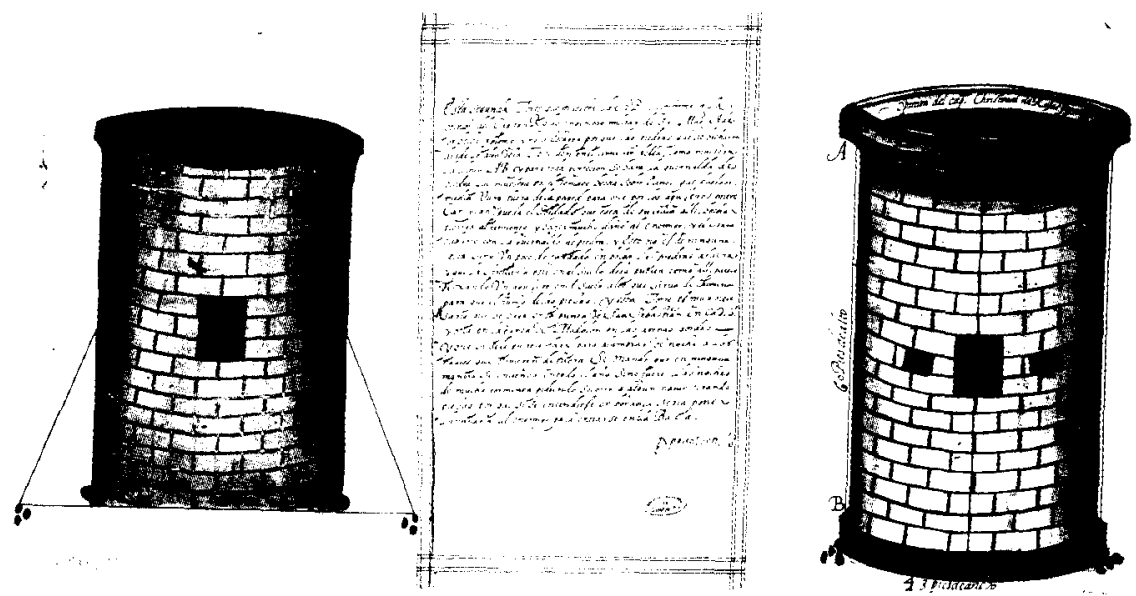

Fig. 6. A. Diseño de tres torres para construir en la costa de Andalucia, por Cristóbal de Rojas. 1613. Archivo General de Simancas.
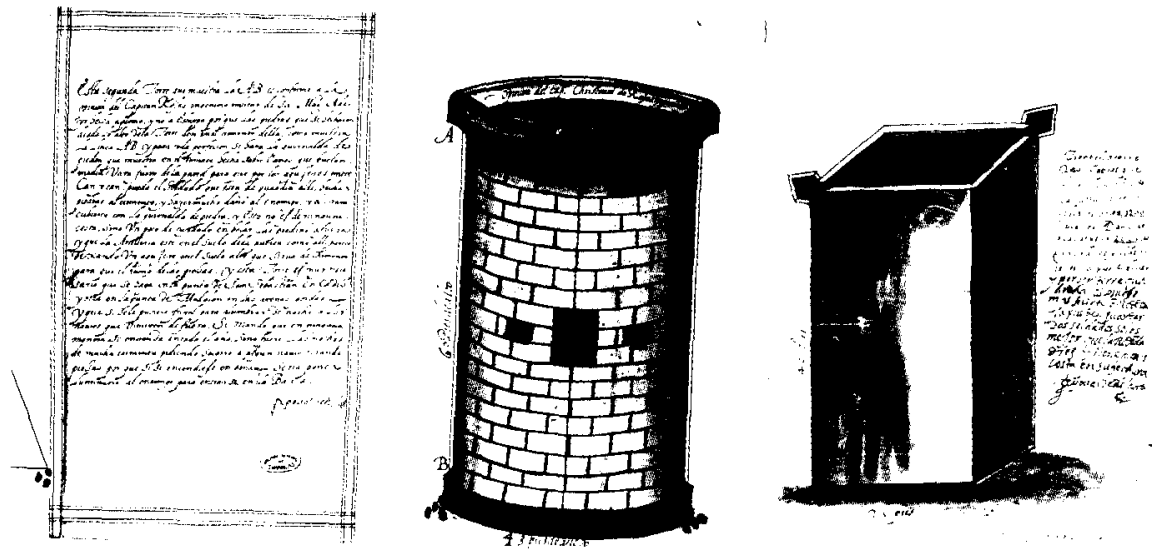

Fig. 6. B. Diseno de tres torres para construir en la costa de Andalucia, por Cristóbal de Rojas. 1613. Archivo General de Simancas. 
de la idea de la almenara), pues podria servir de faro al enemigo para entrar en la bahía. Proponía también Rojas un modelo de torre cuadrada, que consideraba más fuerte que las redondas, además de poder ser guardada por menos soldados. En los escritos de Rojas apenas encontramos referencias a las torres, salvo en el Compendio y breve resolución de fortificación, precisamente del año 1613, en el que se refiere a una torre para cuatro soldados, que después de un cálculo matemático resulta que habría de tener treinta pies de diámetro (poco más de ocho metros) en caso de ser redonda. Dio también intrucciones sobre cómo fundar torres en el agua o pantanos, tanto en ese libro como en otro anterior que permaneció inédito, Sumario de la milicia antigua y moderna, del año 1607, en que propuso un modelo de torre fundada sobre el mar (Fig. 7), pensada en función sólo de la artillería sin alusión a posibles funciones de vigilancia, con lo cual se aparta del modelo de torres que hemos visto hasta ahora ${ }^{9}$.

\section{LA COSTA DEL REINO DE GRANADA}

En la costa del reino de Granada, que es como se siguió llamando a la del antiguo reino nazarí, los cristianos encontraron más torres atalayas hechas de época musulmana que en la costa de Andalucia, pues al parecer treinta y nueve databan de época nazari. Aunque hubo que reforzarlas y/o construir otras nuevas, a comienzos del XVI se tiene noticia de que habia al menos dos en el término de Casares, seis en el de Marbella, seis también en el de Málaga, y cinco en el de Vélez-Málaga, todas ellas con guardas. En el reinado de Carlos I se construyeron varias torres, como la de la Cala del Moral (término de Málaga), y la de Los Lagos en el término de Vélez-Málaga donde también se hizo la de Torrox en el reinado de los Reyes Católicos, pero es en el reinado de Felipe II cuando más atención se concede al tema

${ }^{9}$ Sobre las torres en la costa de Andalucia: MORA FIGUEROA, L.. obra citada; VALDECAN TOS DEMA. R.. "Las torres de vigia de la bahia de Gibraltar", en Actas del Congreso Internacional “El Estrecho de Gibraltar (1987), vol. II. Madrid, 1988. COLECCION APARICI (Servicio Histórico Militar). tomos VII. VIII y XXIII. AGS, GA. leg. 81. f. 445 a 449; leg. 88. f. 161. 162. 163.164 y 300; leg. 110. f. 187; leg. 208 , f. 25 y 57 ; leg. 209, f. 133; leg. 227. f. 168 leg. 234 f. 208,352 y 353 ; leg. 235 . f. 56 ; leg. 240 , f. 8: leg. 249. f. 174 y 182: leg. 250 f. 195: leg. 253. 1. 171: MARIATEGUI. E.. El Capitan Cristobal de Rojas. ingeniero militar del siglo XVi (reed. Madrid. 1985. con los libros que escribio este ingeniero). El memorial con los servicios de Livadote en AGS, GA, leg. 208, f. 46. 


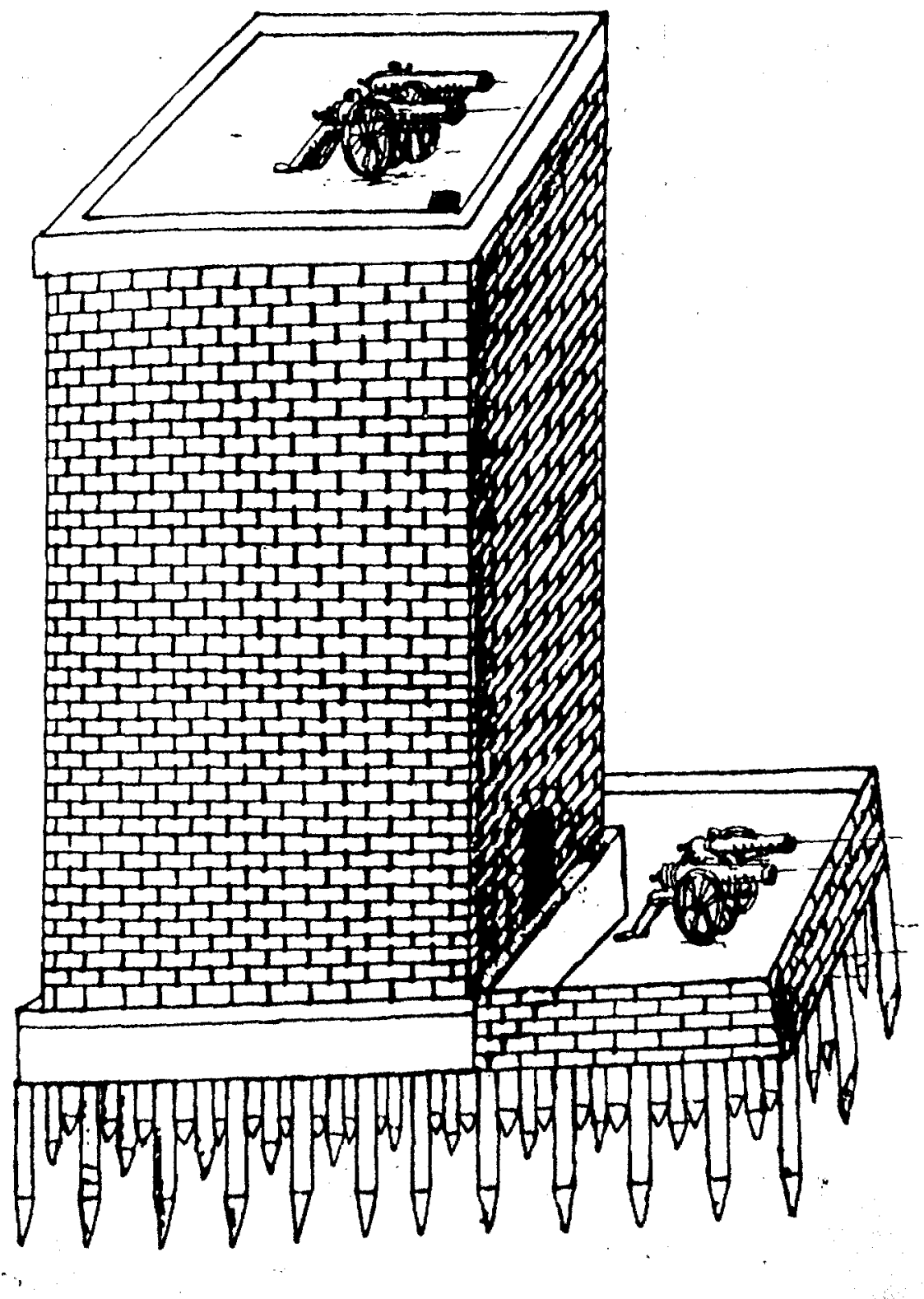

Fig. 7. Cristóbal de Rojas: modelo de torre fundada sobre el mar. (Sumario de la milicia antigua y moderna, 1607). 
En el año 1567 - año de la visita del Maestre de Campo Antonio Moreno y el ingeniero Francisco de Aguilera a las fortificaciones de la costa- se recomendaba hacer las torres del Saladillo y la de la cala de Mochilla, así como reparar la de Roquetas y la del Esparto, pero es de 1575 de cuando data una más completa relación del estado de las torres, hecha según la visita que hicieron a éstas el capitán Antonio de Verrio y el maestro mayor de las obras de la Alhambra, Luis Machuca (quizá se trate de una visita hecha en los años anteriores, pues Luis Machuca moriria en 1571 o 1572, pero su nombre aparece claramente en la relación). En el partido de Marbella recomendaban hacer una torre en la cala de las Adargas, asi como acabar la del Salto de la Mora (Fig. 8) que había empezado el duque de Arcos (abuelo del que lo era ese año de 1575), es esta una torre que Temboury considera musulmana por el tipo de bóvedas utilizadas, similares a otras que existen en edificios musulmanes. Habia que acabar también la de la boca del rio "del Vellerin", la del Saladillo que estaba a dos leguas de Estepona, y la del "Real de Zaragoza" a una legua de Marbella en dirección al levante. Estaban acabadas la de la Celada Vieja, la del Paredón, las Bóvedas, arroyo de la Cruz y Boca del Río del Real de Zaragoza. En el partido de Málaga estaban acabadas las de Calahonda, Calaburras, muelle de Benalmádena (Fig. 9), Cueva de las Palomas, y se habia reedificado la de San Telmo; estaban comenzadas la de la Boca del rio Guadalquivirejo (Guadalhorce), la de Benagalbón y la de Cantal de Vezmeliana, debiéndose comenzar la construcción de la de las Adelfas y la de la Chozuela Vieja una vez que se hubieran acabado las demás por ser estas últimas menos necesarias. En el partido de Vélez-Málaga estaba acabada la de la Boca del río de Vélez, empezadas las de la Boca del río Algarrobo, cerro del Morche, y cala Alhaja, debiéndose hacer la del rio de la Miel y caleta Bermeja. En el partido de Almuñécar y Motril estaban acabadas la torre del Cerro Gordo, la de la punta de Trafalramal, la de la punta de Carchuna, y la del puerto de Cabules, debian acabarse la del Achuelo junto a Almuñécar y la de la cala del Arena junto a Calahonda, debian hacerse las que estaban proyectadas en la Estancia de Baños, rambla de Chilches, rambla de Guarda, estancia del Alcazaba, otra cuatro leguas a! levante de Adra y otra en las Salinas, pues la que se habia hecho era tan «ruyn», además de inacabada, que no servia, recomendándose que se hiciera una nueva torre como las demás de la costa.

Finalmente, en el partido de Almería estaba todo por hacer: las proyectadas eran las de Roquetas, Ramblahonda, Garrofa (estas dos últimas se habian comenzado), las Cubetas y torre Garcia, tres leguas al levante de Almeria; a continuación se presentaba el problema del cabo de Gata, donde, si se quisieran hacer torres en todos los lugares buenos para 


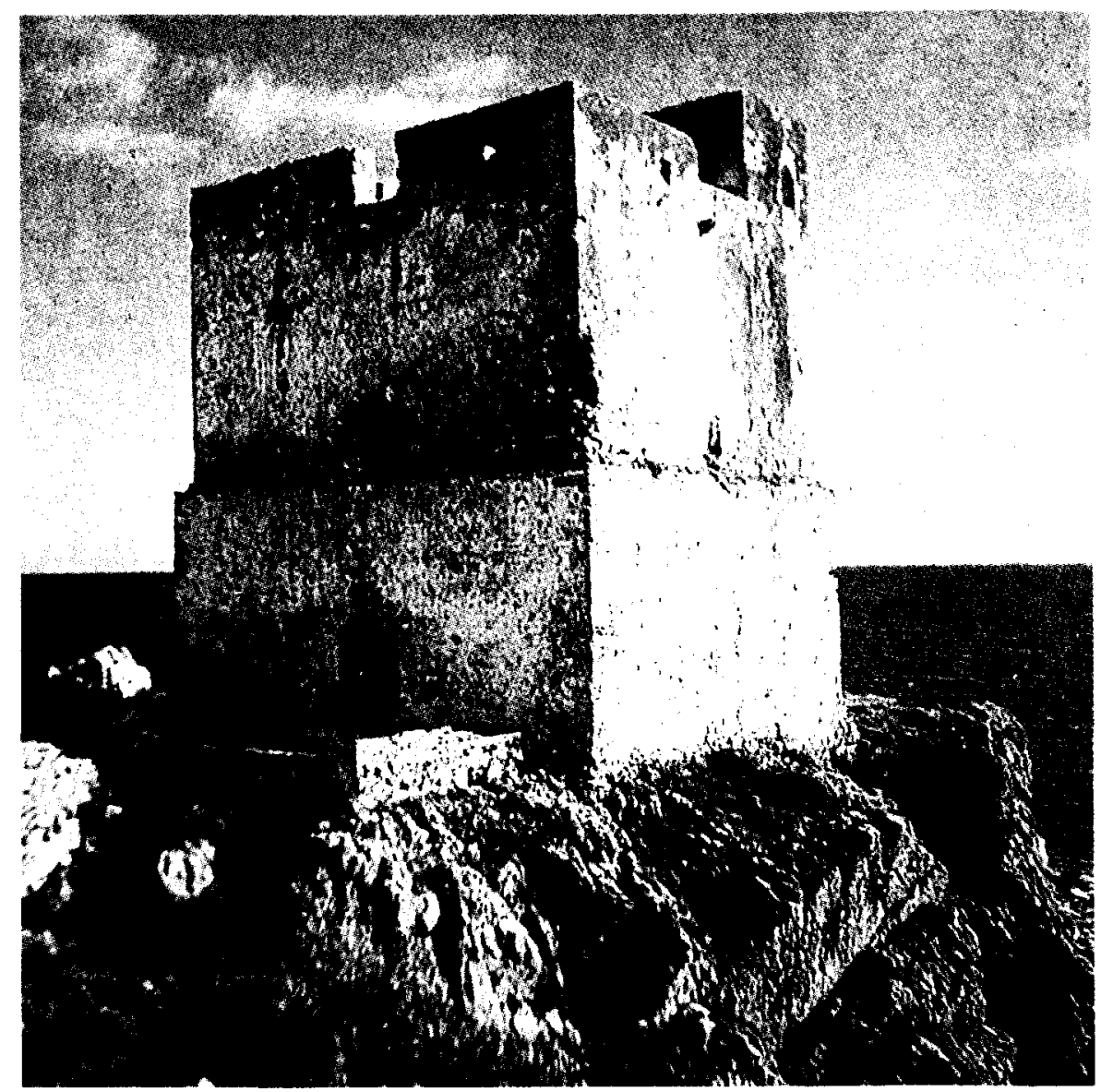

Fig. 8. Torre de Salto de la Mora. Costa del reino de Granada (Malaga). (Tomada de Falcon Márquez).

abrigo de los barcos, harian falta más de veinte, con el inconveniente de que por el relieve del terreno unas a otras no se verian ni podrian dar avisos, por lo cual se habia pensado hacer sólo una en la "testa del cabo" y otra en los pozos de "Chobali» que llamaban cala de San Pedro, teniendo esta última como finalidad el que los enemigos no se aprovisio- 
Las torres del litoral en el reinado de Felipe II: una arquitectura para ...

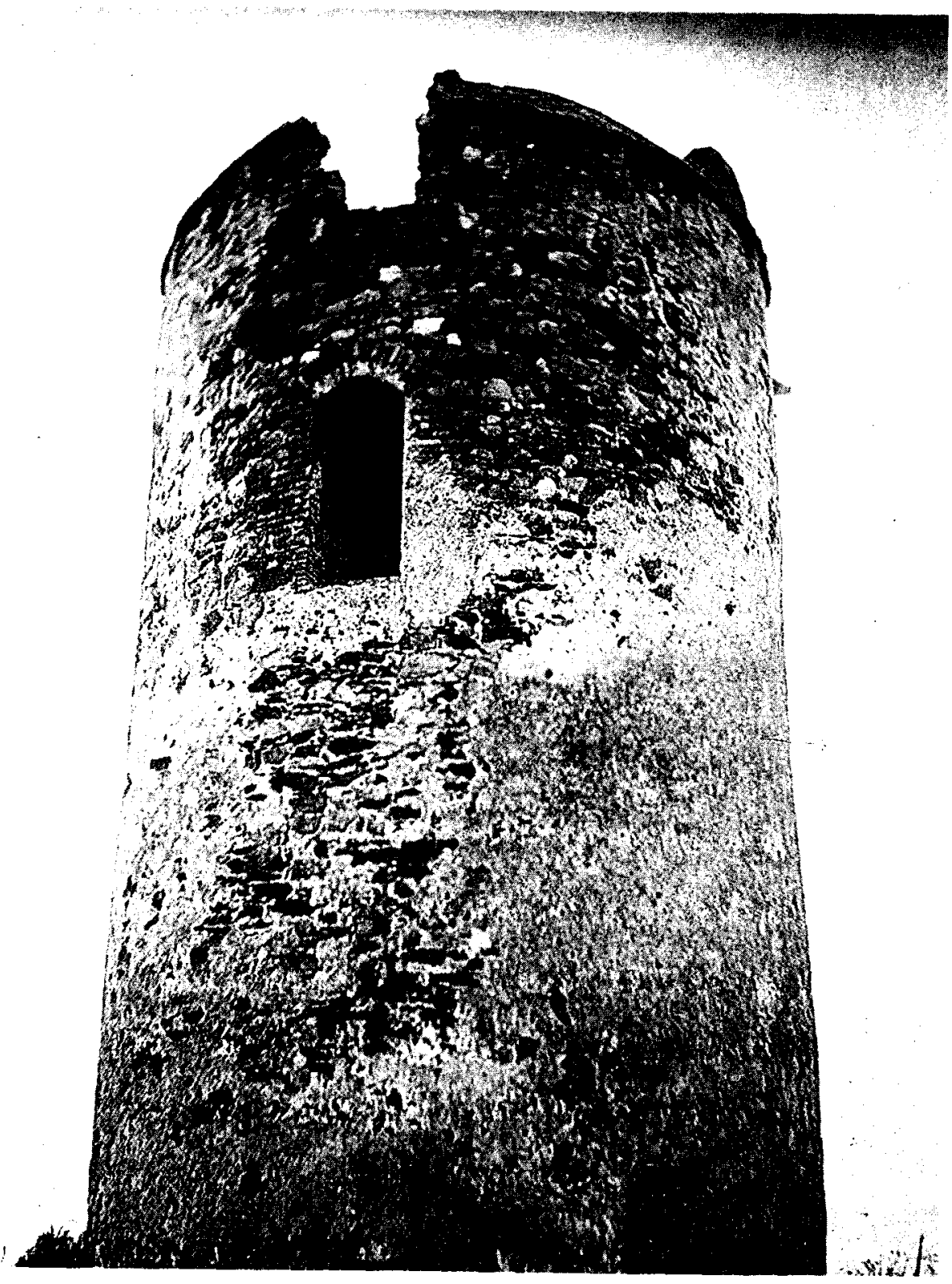

Fig. 9. Torre del muelle de Benalmádena (Málaga). (Tomada de Falcón Márquez). 
nasen de agua con tanta facilidad; las dificultades para la construcción de ésta eran tantas - además del peligro habia que llevar todos los materiales desde Málaga - que recomendaban pagar más al oficial encargado de esta obra. Esta torre de San Pedro en el cabo de Gata consistía a fines del siglo XVII, según una traza que se conserva, en una torre circular de cantería a la que se debía añadir un reducto al que en ese año de 1694 llamaban baluarte. Además de las citadas había que hacer la de Carbonera, la de la estancia de la Granatilla, la de la Guarda vieja, a media legua de Mojácar, la de Garrucha, de la que se mandaba traza (Fig. 11), la de la Boca del rio de Antas (que podia no hacerse si se hacía la de Garrucha), la de la estancia de la Amarguera a dos leguas y media de Vera y la de los Terrenos Blancos, por donde podrían si no los enemigos entrar hasta Huercal (Huercal-Overa).

En esta costa el sistema de torres estuvo jalonado por las fortalezas de las poblaciones más importantes. En sentido contrario al que hemos ido viendo las torres, estas fortalezas fueron: Mojácar, Almería. Adra. La Rábita, Castil de Ferro, Salobreña, Almunécar, Nerja, Torrox, Vélez-Málaga, Málaga, Fuengirola, Marbella y Estepona. Para todas ellas se dieron informes y se repararon sus defensas, pues "estas fortaleças son muy utiles e ymportantes y que se deven conservar y rreparar para que estén en horden ansi para la guarda de la costa como de la tierra adentro", en cambio las fortalezas del interior del reino se abandonaron por no ser ya necesarias.

La construcción de torres almenaras tenia como fin -según escribia en 1584 don Hernando Hurtado de Mendoza a cuyo cargo estaba la guarda de la costa del reinado de Granada- aque con mas brebedad se sepan los abisos en los presidios". En el año 1576 se habla de que habia que hacer en el reino de Granada cuarenta y cinco torres, además de otras quince que habia que reparar, pero a pesar de que en 1580 se nombró ingeniero de la costa del reino de Granada a Ambrosio Malgrat con un sueldo de dieciséis ducados al mes, en el año 1584 quedaban muchísimas torres por hacer y por acabar, siendo un problema grave pues "no pasa el almenara y asi no se estienden los abisos". Ya en el siglo XVII el sistema debia estar en condiciones, pues Henriquez de Jorquera relata dos casos sucedidos en 1640; uno de ellos es bastante explicativo del mecanismo que ponian en marcha estos avisos de las torres: "...a las once de la noche se hicieron almenara en las torres del Alhambra, tocándose a rebato que se descubrió de la atalayas de la costa y a esa hora se pusieron en arma las compañias de la milicia y a las ocho del día llegó correo de la villa de Motril, con que abisó al cavildo 
y correjidor que se abian visto algunas velas a la bista y no sabian si eran de enemigos, de lo qual abisaria un segundo correo..." ${ }^{10}$.

En el año 1584 se enviaron al Consejo varias relaciones sobre el estado de las fortalezas - costeras y del interior - de las cuales resulta (aunque no coinciden exactamente las relaciones) que habia que hacer cinco torres en el partido de Vera y Mojácar, nueve en el de Almeria. cuatro en el de Adra. dos en el de Motril, dos en el de Málaga y tres en el de Marbella, además de reparar otras torres así como fortalezas. Por lo que se refiere a las fortalezas de tierra adentro. una cédula del rey de 1587 ordenaba que no se renovasen los cargos que fueran quedando vacantes «por no ser de ninguna utilidad a mi servicio ni de ninguna fuerça ni defensa en estos mis Reynos».

Sobre los ingenieros que trabajaron en estas torres. sabemos que en 1577 era maestro mayor de la costa de Granada Ambrosio Malgrat, que hizo una visita de ésta en 1580. Muerto en 1587. fue nombrado para sustituirle el ingeniero Juan Pedro Livadote, pero este acabó encargándose de las torres de la costa de Andalucia como ya hemos visto, asi que en 1588 don Alonso de Cárdenas, corregidor de la ciudad de Granada, a cuyo cargo estaba la guarda de la costa de aquel reino, escribia que por fallecimiento del «maestro yngeniero que las veya y tasaba» hacia falta otra persona que se ocupara de las murallas, torres y otras obras para la defensa de la costa; proponía para ello al «maestro que se llama Martin Diez de Navarrete", "havil y sufiçiente y entiende en las obras desta Real Audiençia y a hecho otras aprovadas». Efectivamente ese maestro se habia ocupado de la ejecución de las obras de la Real Chancilleria de Granada, y es este un dato más que prueba cómo la arquitectura militar no fue algo ajeno a la labor de muchos maestros y arquitectos del siglo XVI. Martín Diaz de Navarrete fue nombrado para el cargo, pero no inmediatamente, pues en un documento del año 1593, en una relación que mandó hacer $F$. Hurtado de Mendoza, Capitán General de la costa, de las obras hechas desde el año 1592, se refiere a el como ingeniero de esas obras, y dice que sirve en dicho oficio desde el 14 de diciembre de 1590 con 6.000 maravedies de sueldo al mes. En la relación se da cuenta de algunas de sus funciones: habia ido a ver las obras hechas en la fortaleza de Almeria, habia informado también de que una torre en el partido de Vélez se estaba haciendo mal y había tasado las obras del castillo de Torrox, del torreón del caivo de Gata, de la torre del

16 Henriquez de Jorouera. F., Anales de Granada. Granada. 1987 (reed. de la ed. de 1934). pag. 864. 
Bobar en el partido de Almería, las obras hechas en Castil de Ferro, y las de la fortaleza de Almuñécar. Por cierto que por esta relación nos enteramos de que la torre que se hizo en la testa del cabo de Gata se habia caido cuando estaba a punto de acabarse, asi que se estaba fabricando de nuevo; otra torre (Vela Blanca) en el partido de Almeria la habian derribado los moros y tambien se estaba haciendo nueva: se habia caido la torre de las Salinas en el partido de Adra, y muchas otras torres habian necesitado reparos.

Aunque muchas de estas torres se hayan conservado hasta fecha reciente - algunas todavía permanecen hoy en pie, y otras no han sido destruidas por el tiempo sino por el hombre- da la impresión de que nunca fue posible poner fin a las obras, construyéndose nuevas torres y reparándose las antiguas. Por otra parte, las torres se convirtieron a veces, por la protección que proporcionaban, en el núcleo en torno al cual podia iniciarse una población. En la costa del reino de Granada sabemos de dos casos, siendo la noticia ya de comienzos del XVII: en Motril, en la torre del Varadero "tiene la Villa antes de ahora fabricados unos almacenes, y vivienda de personas que alli tienen trato". y para adecuar la torre a esa nueva situación proponía don Iñigo Briceño en 1626 convertirla en un "reducto" rebajando su altura a la vez que se duplicaba la superficie construida y se añadia un baluarte para cuatro piezas de artillería, con todo lo cual habría sitio para cavallerizas de 20 caballos y vivienda para el alcaide, artilleros, soldados y guardas. El otro ejemplo se encuentra en Nerja. que quedó despoblada después de la conquista, no quedando en el sitio mas que las ruinas de una "torre reducto de tiempo de los dichos moros", arrimadas a la cual se habian ido construyendo casas; eso resultaba peligroso para esa población por lo que se recomendaba que se trasladaran al entorno del castillo de Nerja, donde si podrian tener protección.

Por lo que se refiere a la arquitectura de estas torres, las que se llaman "ordinarias" (que eran la mayoria) debian ser como la del muelle de Benalmádena (Fig. 9) o la torre del Peñón en el partido de Mojácar (Fig. 10), cilindricas (en realidad troncocónicas, pero con un escarpe muy suave). con los huecos precisos para entrar y para vigilar la costa, con un primer cuerpo que siempre es macizo, con una estancia abovedada con chimenea, asi como con una escalera para subir al terrado. Troncocónicas y de mamposteria, con poco más de siete metros de diámetro (algunas llegan a ocho) y entre 10 y 13 metros de alto, asi eran las torres a que se hacia referencia como acabadas o por acabar en la relación de 1575 (salvo la del Salto de la Mora), pero como son también asi otras muchas que no aparecen en dicha relación, podemos concluir 
Las torres del litoral en el reinado de Felipe II: una arquitectura para ...

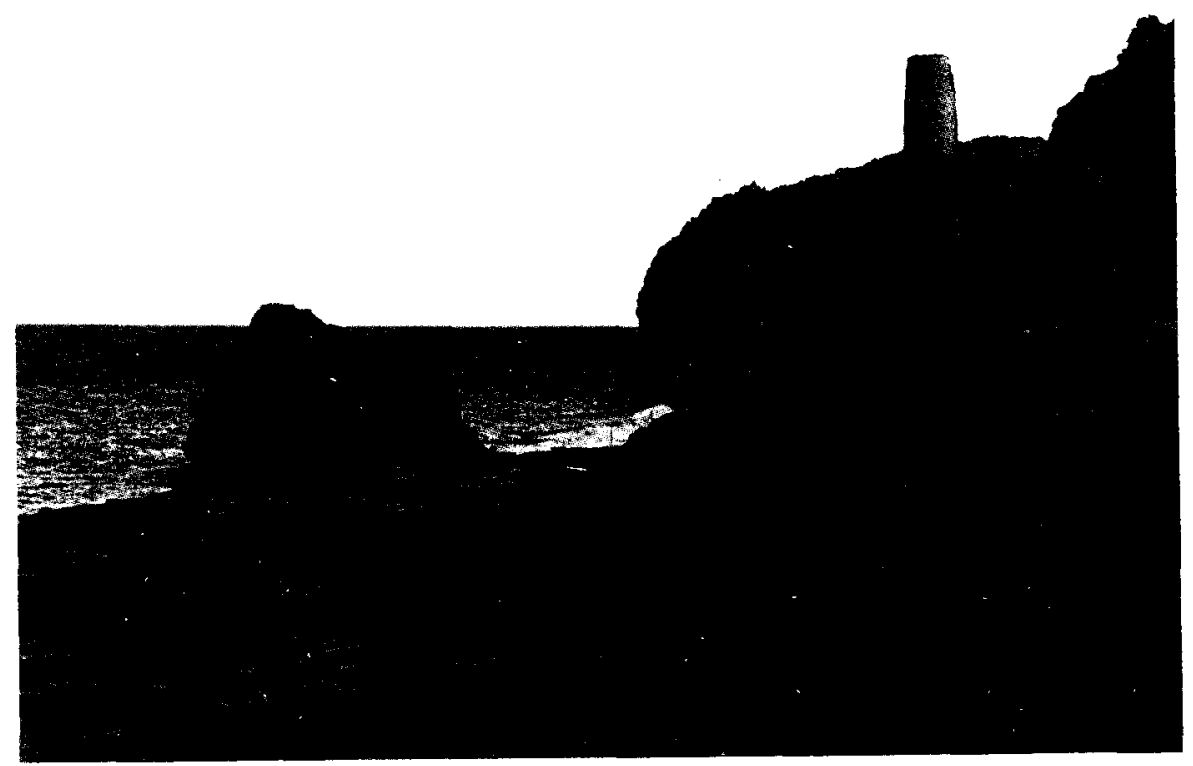

Fig. 10 Torre del Peñón, Mojácar (Almería). 
que hubo un modelo fijo, un patrón para estas torres almenaras, que todos los maestros que contrataron las obras hubieron de seguir.

Por su arquitectura fue una excepción la torre que empezó a construir don Diego López de Haro en el termino de Mojácar. Ya la llamaban "torre de don Diego de Haro" en 1584 y en esa fecha estaba derruida "y se dize esta mandado por su Md que se alçe y haga con su rreduto a de ser la torre de las mayores de veynte y ocho pies en quadro y quarenta y cinco de alto y el Reduto de setenta pies de largo y sesenta de ancho con el grueso de las paredes y aposentos do pueda estar gente de guerra". Por esta descripción sería una torre muy parecida a la que disenó para Garrucha Luis Machuca cuando visitó la costa con el capitán Antonio de Verrio (aunque ya hemos indicado el desajuste de fechas existente entre la fecha de su muerte y la visita) (Fig. 11): por la traza con las medidas vemos que la torre principal tendría unos muros con un ancho de seis pies, teniendo el interior dieciocho, lo cual sumado resulta un ancho de treinta pies, casi los veintiocho que tendría la torre de Diego de Haro; el reducto - «Corral donde se an de rrecoger la gente y xarçias y bestias" como se le llama en la traza - seria en cambio más grande por tener ochenta pies. que con los cinco pies de cada muro sumarian noventa pies de ancho. Quizá sea de ese tipo de "torres cortijos» de que habla Temboury refiriendose a algunas de la epoca de los Reyes Católicos.

A pesar de las coincidencias entre la "torre de don diego de Haro" y la diseñada para Gurrucha. pues eran ambas casi pequenos fuertes en función de una torre principal y ubicadas en la misma zona de costa, no nos atrevemos a identificarlas ya que en 1621 cuando don Iñigo Briceño de la Cueva visitó la costa llevando consigo al ingeniero Juan de Oviedo, las dos torres son diferenciadas en el informe: notificaron al Consejo la necesidad de reparar la torre de la Garrucha en Almeria, cuyo coste debian pagar Vera y Mojácar, pero también se refirieron a otra torre del partido de Mojácar que había sido construida por don Diego López de Haro después de solicitar licencia al rey - le fue concedida el 22 de mayo de 1587- para servir de protección a una almadraba de pescar atunes que pensaba poner en ese lugar; como la almadraba no se llegó a poner, la torre se quedó sin acabar, pero al cuidado de los de Mojácar que protestaban por tal situación.

Las torres de la costa del reino de Granada, debido a la existencia de gran cantidad de ciudades con fortalezas a lo largo de la costa, rara vez debieron ser artilladas (no asi algunas de las de la costa de Andalucía tal como ya vimos), pues su función fue la de almenaras, la de dar 


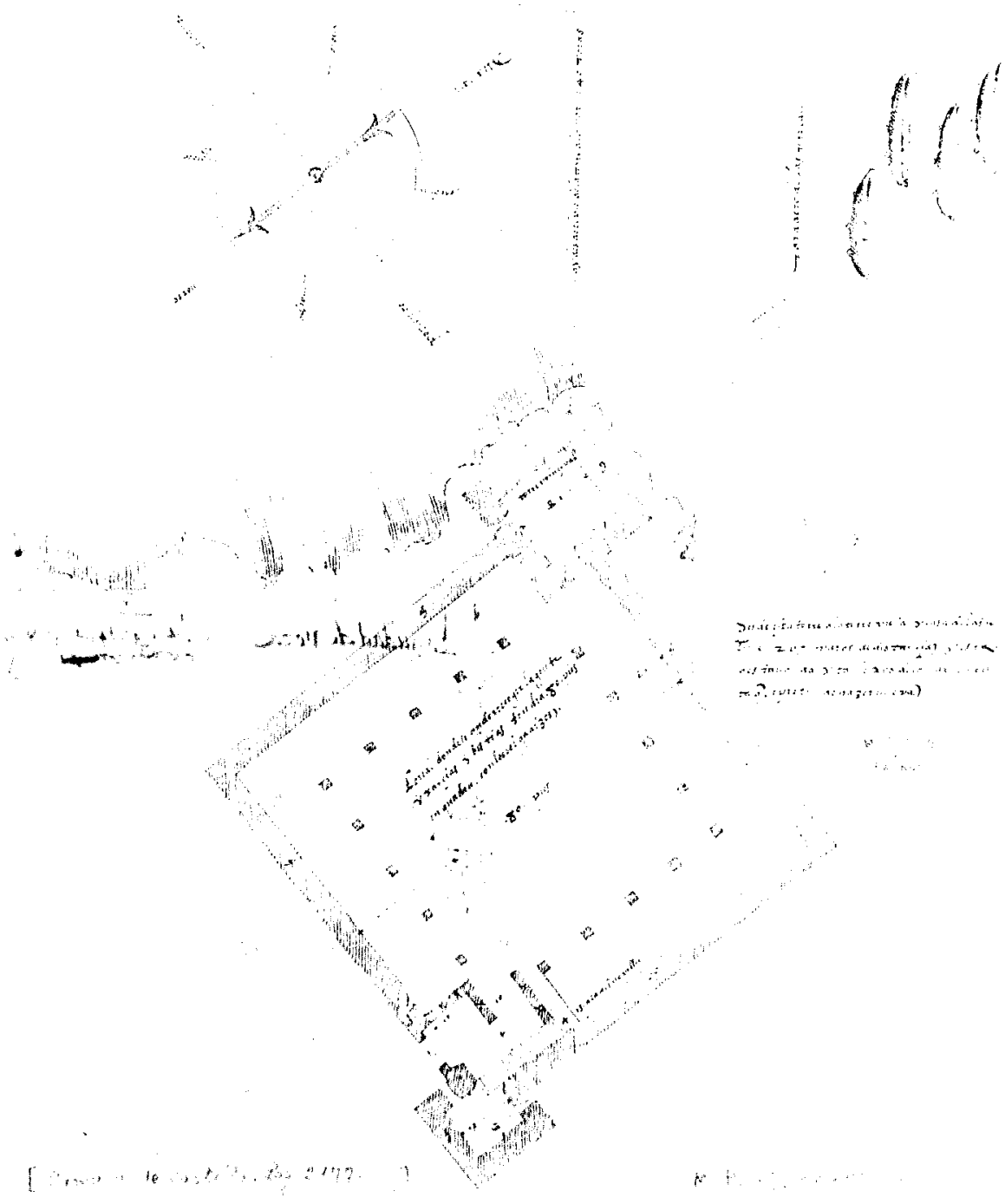

Fig. 11. Diseño de torre para Garrucha (Almería). Archivo General de Simancas. 
aviso del peligro a esas fortalezas, con lo cual es una costa en la que aparte de completar y perfeccionar el sistema, los cristianos fueron en realidad continuadores de un planteamiento defensivo que databa de época nazari ${ }^{1}$.

"Sobre las torres en la costa del reino de Granada: Temboury Alvarez, J.. Torres almenaras (Costa occidental). Malaga. 1975. Falcon Marouez. T., Torres de Almenara del reino de Granada en tiempos de Carlos III. Sevilla, 1989. Gamir Sandoval. obra citada y "Las fortificaciones costeras del reino de Granada, al occidente de la ciudad de Máaga hasta el campo de Gibraltar". Miscelanea de Estudios Arabes y Hebraicos. IX. 1960: BaREA FERRER, J. L., "La figura del ingeniero en el siglo XV!. Sus origenes y su contribucion a la defensa en la costa granadina". Cuadernos de Arte de la Universidad de Granada. XVII. 1985/86; Vera Delgado, A. M. obra citada. Rodriguez Aleman. I., obra citada. Perez de Colosia Rodriguez, I., obra citada. Colección aparicI, tomos VIII Y XXII. AGS. Camara de Castilla, leg. 2177. s. fol.: AGS, GA, leg. 72, f. 76; leg. 81, f. 445: leg. 155, f. 10 y 11; leg. 209, f. 133; leg. 217. f. 35, 37, 38. 45, 77 y 149; leg. 227, f. 158; leg. 228, f. 22; leg. 235 , f. 56; leg. 254 f. 268; Desgraciadamente no hemos podido localizar para su corisulta la tesis doctoral de Barea FerRer, J. L., La defensa de la costa del Reino de Granada en la época de los Austrias, Granada, 1984. 